\title{
Metarretórica, conceito e aplicação: a poética de Augusto de Campos
}

Expedito Ferraz Júnior ${ }^{1}$

\section{Fundamentos teóricos}

O conceito de estilo como desvio em relação a um código pode ser bastante útil na apreciação da poesia experimental, desde que o consideremos de maneira dinâmica. Os estudos retóricos, retomados na atualidade por pesquisadores como os do Grupo $\mu$ (Dubois et al., 1974; 1980), beneficiam-se de contribuições da linguística moderna, da semiótica e das teorias da comunicação, e propõem uma aproximação ao fenômeno poético partindo da abordagem estrutural desses desvios também chamados de figuras ou metáboles - os quais, embora não se restrinjam ao domínio exclusivo do poético, seriam responsáveis por "um efeito estético específico [...] que é o verdadeiro objeto da comunicação artística" (Dubois et al., 1974, p. 66).

Ora, se aceitarmos que o desvio retórico consiste de alterações em relação a uma norma, ou seja, a um hipotético grau zero dos códigos linguístico e literário, é possível perceber o relativismo e a natureza dinâmica desse conceito. Afinal, basta que uma determinada corrente estética se torne dominante para que seus recursos e técnicas mais comuns se institucionalizem como um novo código. Até mesmo no repertório individual de um leitor de poesia, os recursos de estilo que se automatizaram deixam, com isso, de ser desvios e passam a ser normas, em certo sentido. De um ponto de vista retórico, será então continuamente necessário um "desvio do desvio" (Dubois et al., 1974, p. 64), capaz de recuperar e preservar a opacidade do código estético-literário. Desvio e código não podem ser, portanto, noções fixas, mas conceitos em movimento. O desvio será sempre concebido em relação a um estágio determinado da evolução do código. Esta é, pelo menos, a dinâmica da poesia de vanguarda, como teorizou Haroldo de Campos:

O poeta usa o código da língua, em cada obra ou conjunto de obras, como uma espécie de subcódigo individual, personalíssimo. Este

\footnotetext{
${ }^{1}$ Doutor em letras e professor da Universidade Federal da Paraíba (UFPB), João Pessoa, PB, Brasil. E-mail: expeditoferrazjr@gmail.com
} 
código privado e individual, no nível da função poética, vai constituir um idioleto. [...] Quando o idioleto passa a ser integrado no código geral, quando ele vai virando linguagem comum, surgem as convenções acadêmicas, geradoras de novas normas e suscitadoras de novos "desvios da norma" (Campos, 1977, p. 146-147).

Para uma melhor explicação desses processos, considere-se que, na citada Retórica geral, do Grupo $\mu$ (Dubois et al., 1974, p. 71), as figuras ou metáboles estão distribuídas em quatro categorias, como exposto no quadro abaixo.

QUADRO 1 - Metáboles (quadro simplificado)

\begin{tabular}{|c|l|l|}
\hline Categoria & \multicolumn{1}{|c|}{ Descrição } & \multicolumn{1}{|c|}{ Exemplos } \\
\hline Metaplasmos & $\begin{array}{l}\text { Alterações que ocorrem no } \\
\text { aspecto sonoro ou gráfico de } \\
\text { uma palavra, de um conjunto } \\
\text { de palavras ou de uma } \\
\text { unidade de ordem inferior à } \\
\text { palavra. }\end{array}$ & $\begin{array}{l}\text { Apócopes, sinéreses, } \\
\text { rimas, aliterações, } \\
\text { assonâncias, } \\
\text { paronomásias, } \\
\text { neologismos, anagramas, } \\
\text { palíndromos etc. }\end{array}$ \\
\hline Metataxes & $\begin{array}{l}\text { Figuras que agem sobre a } \\
\text { estrutura da frase, alterando a } \\
\text { relação convencional entre os } \\
\text { elementos sintáticos. }\end{array}$ & $\begin{array}{l}\text { Elipses, assíndetos, } \\
\text { parataxe, repetição, } \\
\text { polissíndetos, métrica, } \\
\text { silepses, anacolutos, } \\
\text { quiasmos, tmeses, } \\
\text { hipérbatos etc. }\end{array}$ \\
\hline Metassememas & $\begin{array}{l}\text { Transferência de significados } \\
\text { entre termos de um enunciado, } \\
\text { alterando o sentido de } \\
\text { palavras e expressões }\end{array}$ & $\begin{array}{l}\text { Metáforas, metonímias, } \\
\text { oximoros, sinédoques etc. }\end{array}$ \\
\hline Metalogismos & $\begin{array}{l}\text { Alteração no valor lógico da } \\
\text { frase. }\end{array}$ & $\begin{array}{l}\text { Hipérboles, pleonasmos, } \\
\text { paradoxos, ironias etc. }\end{array}$ \\
\hline
\end{tabular}

Elaboração própria.

Fonte: Dubois et al. (1974, p. 71).

Conservando-se essa divisão geral, mas partindo-se de uma visão das figuras como sistema aberto, no sentido que, certa vez, lhes atribuiu 
Tzvetan Todorov, $^{2}$ pode-se imaginar uma série de operações capazes de promover o entrecruzamento de alguns desses domínios, de forma que, na unidade de um texto, a figura resultante funcione como tradução intersemiótica de outra figura já existente. Uma metáfora, por exemplo, que, de acordo com a divisão proposta, pertence ao conjunto das alterações de natureza semântica (metassememas), pode ser traduzida numa configuração gráfica peculiar (um metaplasmo), e assim por diante. A forma resultante seria uma nova figura, uma atualização do código, um "desvio do desvio".

A forma de atualização retórica mais frequente que identificamos na poética de Augusto de Campos consiste, não em descartar, mas em redimensionar certos procedimentos já convencionais, dando-lhes uma forma imprevista. $\mathrm{O}$ poeta submete determinadas figuras a uma espécie de tradução intersemiótica que, nos termos da função poética de Décio Pignatari, consiste na presença de um sistema icônico "infra, intra e super imposto" à linguagem verbal. ${ }^{3}$

Ao dinamizar a camada sensível (visual, sonora, tátil) do texto verbal, o poema concreto torna-se um campo ideal para experimentações dessa natureza. Trata-se de um procedimento recorrente na poesia de Augusto de Campos, a que gostaríamos de chamar de metarretórica. Poderíamos tratá-lo simplesmente como tradução intersemiótica, mas preferimos sublinhar que se trata, especificamente, da criação de formas equivalentes para determinados processos retóricos - de modo que a tradução se dá entre níveis de construção de um mesmo poema, pois o que se traduz, nesses casos, não é apenas o sentido de um texto, mas sua arquitetura interna. $O$ objeto da metarretórica é o fundamento semiótico de uma metáfora, de um palíndromo, de um anagrama etc. Ao projetar sistemas icônicos sobre estruturas verbais, o poeta cria essas formas complexas, que transitam entre os diversos níveis da construção dos poemas, explorando as relações entre códigos que constituem sua unidade.

\footnotetext{
2 "Temos de dar ao termo figura uma extensão maior, tanto mais que as figuras não passam de relações linguísticas que sabemos distinguir e classificar: é o ato denominativo que faz nascer a figura. A figura que se vai ler nos diferentes níveis da obra pode muito bem não se encontrar no inventário das retóricas clássicas" (Todorov, 1971, p. 258).

${ }^{3}$ A função poética de Pignatari consiste numa releitura daquela formulada por Roman Jakobson (Pignatari, 1979).
} 


\section{Poema bomba}

No primeiro exemplo de metarretórica que escolhemos, epígrafes de Mallarmé ("Je ne connais pas d'autre bombe qu'un livre") e de Sartre ("Le poème est la seule bombe") emprestam ambas sua essência metafórica a um poema cuja estrutura verbal se restringe à repetição do binômio que lhe serve de título. Os substantivos "poema" e "bomba' se alternam em círculos concêntricos formados por caracteres de tamanho crescente (se lidos desde o centro até às margens da página), resultando na imagem de um texto que explode em direção ao leitor.

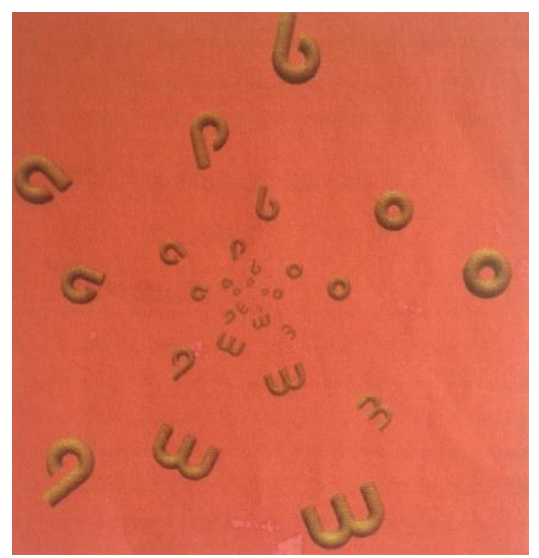

FIGURA 1 - Poema Bomba, versão computadorizada, de 1992.

Fonte: Site de Augusto de Campos. ${ }^{4}$

Considerado o plano semântico do texto (o grupo nominal "poema bomba"), não há dúvida de que a figura sobre a qual se estrutura a mensagem é uma metáfora. Isso se deduz, não só pela referida influência das epígrafes, mas pela consideração do sintagma em si mesmo: temos dois substantivos justapostos, que podem alternar-se na função de nome e de atributo metafórico. Lê-se, então, algo como "poema explosivo" ou "bomba poética". E isso já seria suficiente para o tema bifurcar-se nos sentidos histórico-cultural (numa via de leitura sartreana) e estético (num sentido provavelmente mais afinado com o

\footnotetext{
${ }^{4}$ Disponível em: <http://www2.uol.com.br/augustodecampos/>.
} 
da citação de Mallarmé). Síntese metafórica dessas duas dimensões, o poema surge como atentado à ordem, ou como algo que, explodindo, explode também os códigos: linguístico, estético, cultural etc.

Mas essa operação (transferência de semas, ou traços significativos, entre os dois elementos), que já se apresenta como um desvio retórico (em relação ao sentido, por assim dizer, literal das duas palavras), engendrará outros dois procedimentos, ambos do tipo que ficou acima definido como metaplasmos - quais sejam: i) a já mencionada configuração visual de uma explosão de palavras, com os caracteres figurando um movimento centrífugo que os lança para fora da página ou da tela; e ii) a fusão paramórfica dos termos do sintagma, instaurando uma ambiguidade visual entre os signos poema e bomba. Este último recurso é que, no contexto específico do poema, classificaríamos como metarretórico, como explicaremos adiante. Antes, é interessante analisar mais de perto a natureza semiótica de cada um desses procedimentos.

\section{Uma "explosão" semiótica}

O primeiro metaplasmo, a explosão visual do poema, tem a função de signo icônico do tipo que Charles S. Peirce chamou de imagem. Nos termos da semiótica peirceana, a imagem é uma "primeira primeiridade", isto é, um ícone de natureza sensorial, cuja apreensão se dá de forma imediata. Neste caso, pelo simples ato de olhar a disposição dos elementos na página, de assimilar seus traços qualitativos, percebemos que o poema se assemelha à experiência (real ou ficcional) que temos do que seria uma explosão: a cor vermelha, ao fundo, sugere calor; as letras parecem fragmentos lançados caoticamente no espaço da página. Ainda nesse nível imediato de apreensão, podemos apreender a variação crescente no tamanho das letras como representação de movimento para além da página (ou da tela), como se esses fragmentos/letras se aproximassem, a cada círculo, do leitor.

Nesse aspecto, considerando-se o poema como um signo icônico do tipo imagem - ou seja, uma composição que explora certa relação imitativa entre a forma gráfica e o sentido do texto, representando visualmente seu próprio conteúdo - ele pouco se distingue, em termos conceituais, de experiências anteriores ao poema concreto, na longa tradição que se estende da Antiguidade Clássica aos caligramas do Futurismo, no início do século XX. Contudo, esse nível de leitura não 
contempla o que há de mais inventivo no poema. O texto em forma de é apenas um dos recursos incorporados pelo poema concreto. $\mathrm{O}$ leitor que se restringe a identificar tal recurso tende a simplificar e a desmerecer o conceito de poesia que tem diante de si, do que costumam resultar incompreensões e erros de apreciação. Ora, além dessa iconicidade imagética, há muitas vezes, nos poemas dessa natureza, um segundo nível de iconicidade, a que Peirce chamou de diagramática. Nele, as relações de equivalência são menos evidentes do que na imagem, porque são mais lógicas do que sensoriais. Este é, precisamente, o caso do segundo metaplasmo, que descrevemos a seguir.

\section{Um anagrama tridimensional}

Sem prejuízo dos dois recursos até aqui comentados (a metáfora, no plano semântico, e o ícone imagético, na composição visual), o texto ganhará ainda a forma de um peculiar anagrama, a partir da manipulação gráfica de seus caracteres. Note-se que, embora tenham ambas cinco letras, as duas palavras-temas do texto compartilham, inicialmente, apenas três:

\section{p o e m a \\ b o m b a}

Elas não formariam, portanto, um anagrama, sem a intervenção do poeta sobre o código, naquele que é vem a ser o desvio retórico mais criativo nessa composição. Note-se que, graças ao design gráfico adotado, $p$ e $b$ figuram como uma mesma forma focalizada em ângulos distintos de um suposto movimento de rotação, o mesmo ocorrendo com $m$ e $e$. Assim, de uma correspondência apenas parcial, passa a existir identidade visual entre os dois conjuntos de letras, de modo que o leitor não possa distingui-las ao primeiro olhar.

Não se trata, contudo, de um mero ornamento. O efeito dessa confusão visual entre os signos está inteiramente associado:

1) ao motivo temático da explosão - pois a impressão de movimento caótico que experimentamos justifica-se como efeito de uma espécie de big-bang que atuasse sobre ambas as palavras, fragmentando-as e lançando seus fragmentos em órbitas que se expandem para fora do livro; e 
2) ao sentido da metáfora (transferência/permutação de semas entre duas palavras ou expressões).

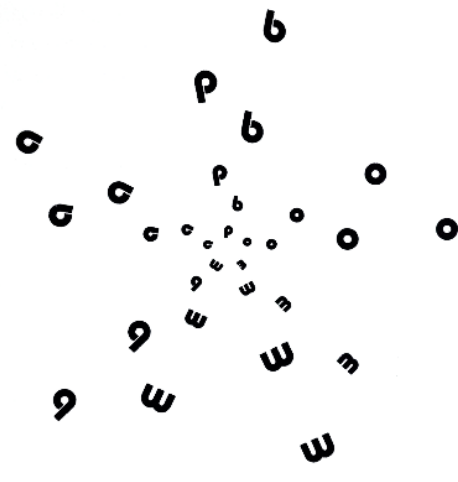

FIGURA 2 - Poema Bomba, versão original, de 1987. Fonte: Campos (1994).

Sobre essa última associação, pode-se afirmar que o anagrama funciona aqui como uma tradução do mecanismo retórico da metáfora. Ora, se a metáfora confunde os significados dos dois termos (afirmando que o poema possui qualidades de bomba, e vice-versa), essa nova figura que o poeta forjou nos faz confundir, analogamente, significantes (lemos poema onde está escrito bomba, e vice-versa). Assim, estabelecese, entre os níveis estruturais do texto, uma relação icônica (de semelhança) do tipo diagramática - equivalência conceitual entre processos distintos, a que Roman Jakobson chamou certa vez de "ícone de relações inteligíveis" (Jakobson, 1995, p. 105). O objeto deste ícone diagramático não é uma coisa concreta a que o texto verbal nos remete. O diagrama não traduz aqui o sentido das palavras do texto, mas o processo retórico que já existia no plano verbal do poema. Retomando a terminologia dos estudos retóricos, podemos dizer que o poeta construiu, no domínio dos metaplasmos, um processo análogo ao que representa a metáfora, no domínio dos metassememas É a essa ordem de analogia que chamaremos de metarretórica, e que julgamos fundamental para a compreensão da poética de AC. 


\section{Viva Vaia}

Um caso semelhante de intervenção metarretórica encontra-se no poema Viva Vaia, de 1972. Tendo como figuras de base a antítese e o oximoro, o poema busca certa identidade paradoxal entre as ações de aplaudir e rechaçar, com a consequente desautomatização dos usos que o código cultural lhes atribui. Para tanto, o poeta investe na semelhança gráfica entre as duas palavras-tema e, por meio de um design estilizado, reduz $V$ e $A$ a formas idênticas (procedimento que se repetiria, mais tarde, no Poema Bomba, como vimos). Nesse caso, porém, os conceitos de equivalência e de antagonismo continuam presentes na estrutura simétrica resultante.

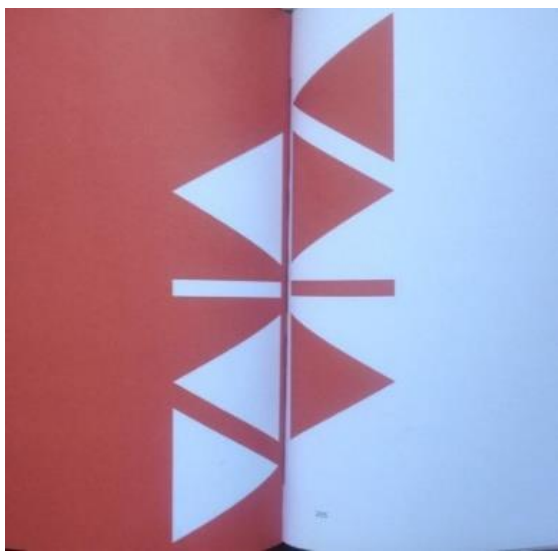

FIGURA 3 - Viva Vaia, de 1972.

Fonte: Campos (2000).

Considerando-se, inicialmente, a composição em sua estrutura verbal, vemos que a aproximação entre as duas palavras-tema pode suscitar, no texto, certa polissemia de natureza sintático-semântica. Além da função de interjeição (geralmente associada a aplauso ou aclamação), viva pode ser também: i) um verbo no imperativo, tendo vaia como complemento; ii) um adjetivo que modifica o segundo termo; e, simplesmente, iii) o primeiro de dois substantivos justapostos. Vaia, por sua vez, além de substantivo, também pode atuar como: i) verbo no presente do indicativo, tendo viva (substantivado) como sujeito da ação de vaiar; e ii) atributo do primeiro termo, se a estrutura é puramente nominal. O sentido mais evidente, em 
todos esses casos, é o de uma aproximação entre contrários que, todavia, não chegam a se anular mutuamente. As figuras de retórica resultantes dessa aproximação são a antítese (que pertence ao domínio dos metalogismos, "as antigas figuras de pensamento") (Dubois et al., 1974, p. 71) e o oximoro (que está situado no campo dos metassememas).

Em todas as hipóteses, ressalta-se a relativização dos dois conceitostema: não há como se manter intacto o sentido de uma palavra, quando esta surge emparelhada com o seu oposto, e menos ainda quando esse emparelhamento é reforçado pela semelhança dos significantes. Mas o que afirma, precisamente, essa composição? Existiria um referente específico para a potencial narrativa dessa vaia ou desse aplauso que se invertem? A princípio, o poema abarcaria um contexto muito amplo, referindo-se a qualquer situação (um fato estético, um discurso político etc.) em que algo ou alguém se coloca publicamente, estando exposto a aplauso ou reprovação. À falta de outros elementos referenciais, todavia, é o próprio contexto da enunciação poética que atrai para si essa condição da coisa exposta, solicitando uma leitura metalinguística. Então, podemos supor que o poema que se abre diante de nós é também o objeto em face do qual os gestos de aprovar e reprovar se relativizam ou se confundem o que não exclui, entretanto, que se atribua, por extensão, essa mesma condição à poesia, à literatura, ou a arte, de modo geral.

Nesse caso em particular, algumas informações contextuais, relacionadas às formas de veiculação e de recepção do poema, oferecem-se como elementos acessórios nessa leitura metalinguística. É relevante, por exemplo, sabermos que o poema ilustra as capas do volume que reuniu a poesia de AC produzida entre 1949 e 1979, tendo-se tornado o tema do projeto gráfico de Júlio Plaza, que o empregou como uma espécie de padrão geométrico, ao modo da pintura concretista. Com isso, Viva Vaia passou a ser lido também como título do volume, desde a primeira edição (Duas Cidades, 1979), o que se manteve na reedição, em 2000, da Ateliê Editorial. Finalmente, há o dado, revelado em depoimentos posteriores, de que o poema aludia, entre outros acontecimentos, à reação violenta do público a uma apresentação do cantor e compositor Caetano Veloso durante o Festival Internacional da Canção, em 1968 (não é à toa que a primeira edição do livro de AC trazia encartado um disco compacto de vinil com o registro de dois outros poemas da coletânea musicados pelo artista baiano). Nesse sentido, convém lembrar ainda a citação de 
Jean Cocteau, que o poeta tomou como epígrafe do livro: "Aquilo que o público vaia, cultive-o, é você." 5 Por todas essas circunstâncias, Viva Vaia se tornaria uma espécie de emblema da atitude do poeta diante da hostilidade, de certa parcela do público leitor, ao conceito de poesia que sua obra representa. Sua estrutura simétrica materializa, no relativismo de sua forma, uma visão dialética do processo de comunicação pela arte, na medida em que insemina de êxito o signo correspondente ao fracasso, e vice-versa.

Tomado o poema em seu aspecto visual, ressalta-se o efeito de equilíbrio matemático, de simetria, do conjunto. Em cada metade há quatro letras, das quais surgem dois conjuntos internos, que também têm estrutura simétrica: $V I V$, numa extremidade; $A I A$, na outra. Com a estilização de $V$ e $A$, representados por uma mesma forma triangular, define-se a completa identidade entre os conjuntos. Além disso, o quarto elemento de cada metade é justamente aquele que predomina na metade inversa ( $A$, no segmento VIV; $V$, no segmento AIA). É como se, substituindo-se as curvas por linhas retas e formas geométricas, a arquitetura do poema obedecesse ao mesmo princípio que rege a representação do yin yang: dois polos de natureza antitética, mas que guardam, cada um deles, a essência do seu contrário, de modo que a relação entre os polos se resolva num equilíbrio dinâmico.

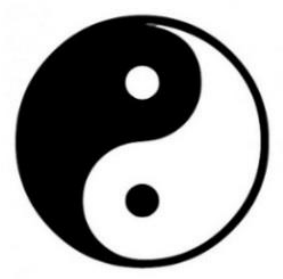

FIGURA 4 - Yin Yang.

Perceber os efeitos provenientes dessa configuração é metade do percurso da leitura do poema. A outra metade consiste em identificar a função que lhes cabe na relação entre os níveis sígnicos da composição,

\footnotetext{
${ }^{5}$ No final dos anos 1990, também o website do poeta adotaria o poema como tema visual. Disponível em: <http://www2.uol.com.br/augustodecampos>. Acesso em: 28 jan. 2016.
} 
vale dizer: na relação entre os códigos verbal e não verbal, aqui envolvidos. O que o aspecto visual do poema nos diz sobre sua mensagem verbal? Diferentemente do que ocorre no Poema Bomba, a forma, nesse caso, não é de natureza figurativa, mas geométrica. Consequentemente, o leitor não encontrará um referente externo a que possa associar de imediato o seu desenho (não há um ícone do tipo imagem). Mas isso não quer dizer que essa estrutura geométrica seja aleatória ou privada de sentido: trata-se de um diagrama das relações lógicas já presentes em sua construção verbal. Assim, toda a distribuição simétrica dos elementos no espaço da página - o equilíbrio no número de elementos gráficos em cada lado do poema; o jogo cromático entre o vermelho e o branco, que se alternam como fundo e forma; e os triângulos com vértices que apontam para direções opostas - todo esse arranjo reflete, no nível não verbal, a antinomia que há entre as duas palavrastema. Mas, ao mesmo tempo, o relativismo que descrevemos acima, e que comparamos à arquitetura lógica do Yin Yang, faz com que essas relações evoluam do mero contraste para a expressão de uma harmonia de contrários. Não por acaso, o mesmo signo gráfico pode ser lido como "viva" ou como "vaia", dependendo do ângulo da leitura, numa espécie de palíndromo sus generis. E mais uma vez temos uma figura que traduz outras figuras. Nesse caso, o conjunto dos metaplasmos que acabamos de descrever transpõe para a estrutura gráfica do poema outras duas figuras: a antítese (que pertence ao domínio dos metalogismos) e o oximoro (situado no campo dos metassememas).

\section{Anticéu}

O terceiro exemplo de metarretórica que abordamos é "Anticéu", datado de 1984 e publicado na coletânea Despoesia (ed. Perspectiva), dez anos mais tarde. Esse poema apresenta o que se poderia definir, a princípio, como um esquema retórico convencional, baseado numa metáfora in praesentia que envolve os temas do "cosmos" e da "poesia" associação muito frequente na poesia de AC. 


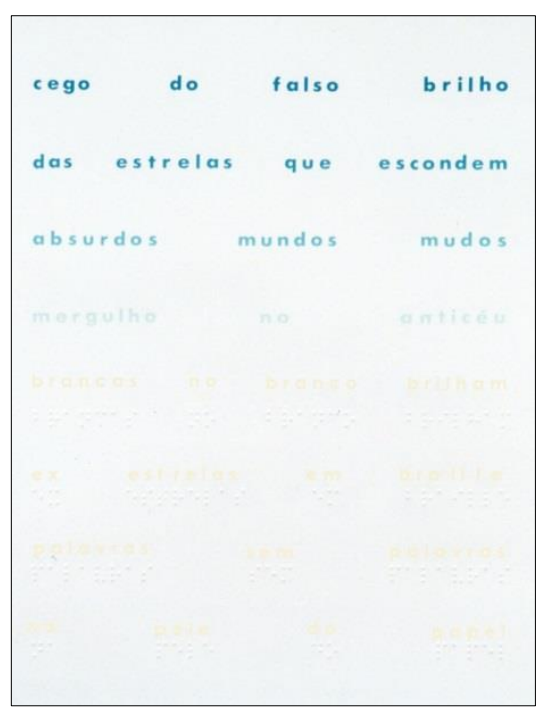

FIGURA 5 - Anticéu, de 1984.

Fonte: Campos (1994).

Como toda construção metafórica, essa também exige do leitor que aceite sua ambivalência semântica. Deve-se ter consciência, portanto, de que o texto fala, ao mesmo tempo, de ler "palavras" e "estrelas". Em qualquer dessas chaves, vemos, num discurso em primeira pessoa, a recusa a um "falso brilho" e a escolha por um "anticéu", em que "brilham ex estrelas em braille". Há, portanto, uma polarização entre o que é ostensivo, mas ilusório, e o que é verdadeiro, mas invisível, só podendo ser percebido a partir de um aperfeiçoamento dos sentidos. O poema é, portanto, uma celebração da "beleza difícil": "cego do falso brilho / das estrelas que escondem / absurdos mundos mudos / mergulho no anticéu / brancas no branco brilham / ex estrelas em braille / palavras sem palavras / na pele do papel".

Reforça essa argumentação, ainda no plano semântico, o recurso da sinestesia, pois o texto também se divide em dois polos: nos primeiros versos, predominam os semas relacionados à visão, ainda que o eu-lírico se declare "cego" a esses estímulos: "brilho", "estrelas", "mundos". $\mathrm{Na}$ segunda metade, surgem expressões como "braille" e "pele do papel", num deslocamento dos estímulos sensoriais tematizados, que migram da visão para o tato. A expressão "brilham... em braille" marca 
precisamente o momento dessa transição, na medida em que funde metaforicamente os dois campos semânticos.

Todo esse arranjo encontrará sua tradução em dois recursos: a impressão em dégradé (que parte do azul celeste e vai esmaecendo em direção ao branco) e a versão em braille da metade invisível do texto, que se inicia, significativamente, no verso "brancas no branco". Esses recursos produzem o que Charles Perrone chamou de "sinestesia real" "a unique true synesthesia of the visual and the tactile" (Perrone, 1996, p. 153). De fato, ao mesmo tempo que o plano verbal tematiza o deslocamento do visual para o tátil ("cego do falso brilho... mergulho no anticéu"), o poema vai se tornando gradativamente inapreensível pelos olhos, enquanto nos oferece a leitura do texto em braille.

Também nesse caso, impõe-se à leitura a consideração dos signos icônicos em duas dimensões: a iconicidade imagética e a diagramática. Observe-se a ambivalência na forma dos signos braille: eles tanto podem representar visualmente a forma de constelações, como, por sua destinação ao tato, emprestam concretude ao tema da cegueira. Traduzem, assim, ao mesmo tempo, a metáfora (signos/estrelas) e o recurso retórico da sinestesia. No primeiro caso, lê-se uma imagem (um ícone visual do referente "estrelas"); no segundo, associando-o à invisibilidade da metade do texto, lê-se um diagrama - uma relação de analogia entre o deslocamento semântico e o "real" ou sensorial. Embora o aspecto cromático e o emprego do braille não sejam figuras previstas no inventário dos estudos retóricos tradicionais, atuam aqui como desvios de natureza metaplástica, repercutindo na camada sensível do poema os desvios de natureza semânticos, já convencionais.

\section{Considerações finais}

Exemplos como os que acabamos de descrever nos autorizam a considerar esses processos (que aqui chamamos de metarretóricos) como um dos traços que orientam e distinguem a poética de AC. Há, nessa constatação, pelo menos uma consequência que julgamos útil para a leitura de sua obra. Diz respeito à função desempenhada nos poemas pelas informações não verbais. Em geral, sabe-se que os arranjos gráficos/espaciais desses poemas respondem por uma função icônica ou seja, que a escolha das cores, do design e da distribuição do texto no espaço gráfico servem para representar, através de suas qualidades 
sensíveis, determinados temas, seus objetos. Entretanto, é incorreto esperar que a forma das composições se assemelhe sempre a um referente externo tematizado pelo poema, como ocorre nos chamados pictogramas. Os casos de que tratamos aqui demonstram que, além desse tipo de iconicidade (exofórica), ocorre também, na poesia em estudo, certos efeitos de similaridade na relação entre partes ou mecanismos internos ao poema (Nöth, 2003, p. 104-121).

Assim é que, nos textos comentados, o poeta se utiliza, como vimos, de recursos gráficos variados para traduzir em formas sensíveis determinados desvios retóricos. Em outras palavras, não será possível apreender plenamente o efeito estético de uma composição como o "Poema Bomba" se nos ativermos apenas à representação do tema da explosão, ignorando a representação do processo metafórico que embaralha visualmente as duas palavras-tema. Assim como não será completa a apreensão de "Viva Vaia" se apenas contemplarmos a simetria do seu design geométrico, sem percebermos nela a referência ao oximoro. Nem será completa, enfim, a leitura de "Anticéu" se apenas notamos a semelhança fisionômica entre signos e estrelas, sem identificarmos, no jogo entre o visível e o invisível, na relação entre os alfabetos romano e braille, a tradução do efeito retórico da sinestesia.

\section{Referências}

CAMPOS, Augusto de (1994). Despoeisa. São Paulo: Perspectiva.

CAMPOS, Augusto de (2000). Viva Vaia: poesia, 1949-1979. 2. ed. São Paulo: Ateliê.

CAMPOS, Haroldo de (1977). Comunicação na poesia de vanguarda. In: CAMPOS, Haroldo de. A arte no horizonte do provável. São Paulo: Perspectiva, p. 146-147.

DUBOIS, Jacques et al. (Grupo $\mu$ ) (1974). Retórica geral. São Paulo: Cultrix.

DUBOIS, Jacques et al. (1980). Retórica da poesia. São Paulo: Cultrix.

JAKOBSON, Roman (1995). À procura da essência da linguagem. In: JAKOBSON, Roman. Linguística e Comunicação. 15. ed. São Paulo: Cultrix, p. 98-117.

NÖTH, Winfried (2003). Panorama da semiótica: de Platão a Peirce. 3. ed. São Paulo: Annablume. 
PERRONE, Charles A. (1996), Seven faces: Brazilian poetry since modernism. Londres: Duke University Press.

PIGNATARI, Décio (1979). Semiótica e literatura: icônico e verbal; Oriente e Ocidente. 2 ed. São Paulo: Cortez \& Moraes.

TODOROV, Tzvetan (1971). Como ler? In: TODOROV, Tzvetan. Poética da prosa. Lisboa: Edições 70, p. 258.

Recebido em maio de 2016.

Aprovado em agosto de 2016.

\section{resumo/abstract/resumen}

\section{Metarretórica, conceito e aplicação: a poética de Augusto de Campos}

Expedito Ferraz Júnior

A forma de atualização retórica mais frequente que identificamos na poética de Augusto de Campos consiste em redimensionar certos procedimentos estéticos já convencionais, dando-lhes uma forma imprevista. O poeta submete determinadas figuras a uma espécie de tradução intersemiótica que, nos termos da função poética de Décio Pignatari, envolve a presença de um sistema icônico "infra, intra e super imposto" à linguagem verbal. O presente trabalho propõe uma abordagem desse aspecto da poesia em estudo, a que chamamos de metarretórica, aplicando-o à leitura de alguns poemas ilustrativos do poeta paulista.

Palavras-chave: Augusto de Campos, poesia, figuras, semiótica.

\section{Meta-rhetoric, concept and application: the poetics of Augusto de Campos}

Expedito Ferraz Júnior

The most prevalent form of rhetoric innovation we have identified in Augusto de Campos' poetry the reframing of certain conventional aesthetic procedures, which endows them with an unexpected facet. The poet approaches certain figures of speech via an intersemiotic translation that, according to Décio Pignatari's poetic function, involves the presence of a symbolic system that operates "below, intra and super" when imposed to verbal language. This essay proposes to approach Campos' poems through what we call a meta-rhetoric perspective.

Keywords: Augusto de Campos, poetry, figures, semiotics. 


\section{Metarretórica, concepto y aplicación: la poética de Augusto de Campos}

Expedito Ferraz Júnior

La forma más frecuente de actualización retórica que hemos identificado en la poética de Augusto de Campos consiste en la reformulación de ciertos procedimientos estéticos ya convencionales, dándoles una forma inesperada. El poeta somete ciertas figuras a un tipo de traducción intersemiótica que, como afirma la función poética de Décio Pignatari, implica la presencia de un sistema icónico "infra intra e super impuesto" en el lenguaje verbal. Éste trabajo propone un enfoque de estos aspectos en la poesia en estudio, que denominamos metarretórica, aplicándolo en el análisis de algunos poemas ilustrativos del poeta brasileño.

Palabras clave: Augusto de Campos, poesía, figuras, semiótica. 